\title{
IDENTIFICAÇÃO DE DEMANDAS DE PROJETO EM APARTAMENTO PARA USUÁRIOS IDOSOS POR MEIO DE MODELOS FÍSICOS
}

\author{
IDENTIFICACIÓN DE DEMANDAS DE PROYECTO EM PARTAMENTO PARA USUÁRIOS IDOSOS POR \\ MEDIO DE MODELOS FISICOS
}

IDENTIFICATION OF DESIGN DEMANDS IN APARTMENT FOR ELDERLY USERS THROUGH MODELS

\section{RODRIGUES, RODRIGO}

Mestre em Arquitetura e Urbanismo, UEL, rodrigosrodrigues@hotmail.com

\section{IMAI, CÉSAR}

Pós-Doutorado pelo Instituto de Arquitetura e Urbanismo da Universidade de São Paulo ,UEL , cesarimai@gmail.com

\section{RESUMO}

O crescimento da população idosa no Brasil desperta a necessidade do avanço em estudos sobre o meio espacial, principalmente, a habitação. Com o processo de verticalização nas cidades brasileiras, entende-se que é importante aferir a produção contemporânea de apartamentos e extrair dela elementos que possam alimentar projetos. Portanto, este artigo tem como objetivo verificar a viabilidade do uso de modelos tridimensionais físicos como protótipos de simulação de ambientes habitacionais que possibilitem identificar requisitos em relação às necessidades desses usuários. 0 protótipo utilizado foi desenvolvido a partir do uso de cortadoras a laser e impressora 3D, e possui uma escala maior do que a comumente utilizada em representações e certa flexibilidade, que permite fazer alterações de projeto junto ao usuário em um processo participativo. Para auxiliar na coleta de informações foi elaborado um protocolo de procedimentos de aplicação da simulação, com uma entrevista que buscou informações sobre a opinião dos usuários durante o processo e um questionário ao final do mesmo. Os dados coletados permitiram identificar que levar o usuário a simular algo que nunca imaginou, traz-lhe a possibilidade de avaliar questões, ampliando os seus conhecimentos e permitindo refletir sobre aspectos que poderiam acarretar problemas no uso do apartamento. A identificação de semelhanças do modelo com ambientes reais incentivou a interação do usuário com o protótipo, permitindo, assim, extrair algumas informações que outras ferramentas usadas de forma isolada, como as entrevistas e questionários, por exemplo, não são capazes de captar.

PALAVRAS-CHAVE: Modelo tridimensional; Idosos; Simulação; Habitação; Apartamento.

\section{RESUMEN}

El crecimiento de la población anciana en Brasil despierta la necesidad del estudios sobre el medio espacial, principalmente, la vivienda. Con el proceso de verticalización en las ciudades, es importante evaluar la producción de apartamentos y extraer elementos que puedan alimentar proyectos. Así, este artículo tiene como objetivo verificar la viabilidad del uso de modelos tridimensionales físicos como prototipos de simulación de ambientes habitacionales que identifiquen requisitos en relación a las necesidades de esos usuarios. El prototipo utilizado fue desarrollado a partir del uso de cortadoras láser e impresora 3D, y posee una escala mayor que la comúnmente utilizada en representaciones y cierta flexibilidad, que permite hacer cambios del diseño junto al usuario en un proceso participativo. Para ayudar en la recolección de informaciones fue elaborado un protocolo de procedimientos de aplicación de la simulación, con una entrevista que buscó informaciones sobre la opinión de los usuarios durante el proceso y un cuestionario al final del mismo. Los datos recolectados permitieron identificar que llevar al usuario a simular algo que nunca imaginó, le trae la posibilidad de reflexionar cuestiones, ampliando sus conocimientos y permitiendo reflexionar sobre aspectos que podrían acarrear problemas en el uso del apartamento. La identificación de similitudes del modelo con espacios reales incentivó la interacción del usuario con el prototipo, permitiendo así extraer algunas informaciones que otras herramientas usadas de forma aislada, como las entrevistas y cuestionarios, no son capaces de captar.

PALABRAS CLAVE: Modelo tridimensional; los ancianos; la simulación; Apartamento.

\section{ABSTRACT}

The growth of the elderly population in Brazil raises the need for advancement in studies on the space, mainly housing. With the verticalization process in Brazilian cities, it is important to assess the contemporary production of apartments and extract from them elements that can feed projects. This article aims to verify the feasibility of using three-dimensional physical models as prototypes of simulation of housing environments to identify requirements in relation to the needs of these users. The prototype used was developed from the use of laser cutters and 3D printer, and has a larger scale than commonly used in representations and a certain flexibility, which allows to make design changes with the user in a participatory process. A protocol of procedures for the application of the simulation was elaborated, with an interview that sought information about the users' opinions during the process and a questionnaire at the end of it. The data collected allowed us to identify the user to simulate something he never imagined, which allows him to evaluate questions, expanding his knowledge and allowing him to reflect on aspects that could lead to problems in the use of the apartment. The identification of similarities of the model with real environments encouraged the interaction of the user with the prototype, thus allowing to extract some information that other tools used in isolation, such as interviews and questionnaires, for example, are not able to capture. KEYWORDS: Three-dimensional model; Seniors; Simulation; Housing; Apartment. 


\section{INTRODUÇÃO}

O envelhecimento ${ }^{1}$ é um fator presente na maioria das sociedades, principalmente nos países desenvolvidos, e vem crescendo nos países subdesenvolvidos, como no Brasil (FISCHER; SILVA FILHO, 2010). Em uma pesquisa sobre o envelhecimento, Fuentes et al. (2010) levam os entrevistados a pensar sobre sua velhice futura. Nesse sentido, questões como quais moradias são mais adequadas ao novo perfil dos usuários idosos devem fazer parte da reflexão atual da sociedade.

Paralelamente a essa condição, vê-se nas cidades o processo de verticalização como uma das possíveis soluções para o crescimento da população e, por consequência, o aumento das habitações coletivas. No Brasil, o surgimento das moradias em apartamentos remonta à primeira década do século XX, quando as principais cidades passaram por importantes remodelações urbanísticas, conferindo ao modelo de habitação convencional - as casas térreas, novas possibilidades formais e programáticas (VILLA; SARAMAGO; PIRES, 2014). Para Queiroz e Tramontano (2009), os edifícios verticais de apartamentos representam uma grande opção à parte da população e suas unidades compõem grande parcela do produto imobiliário novo no país.

O envelhecimento da população, atrelado ao crescimento da verticalização nas cidades, indica a importância de se avaliar a produção atual de apartamentos e que dela sejam extraídos elementos capazes de contribuir para o processo de projeto. Assim, o objetivo principal desta pesquisa consiste em identificar como o uso de um modelo físico, em um procedimento de simulação de aspectos funcionais e ergonômicos da moradia, possibilita auxiliar na identificação de demandas e requisitos espaciais dos usuários idosos em projetos de apartamentos. Além disso, também foram desenvolvidos procedimentos metodológicos para aplicar na simulação que buscam ser mais adequados para esse perfil de usuários.

O recorte desta pesquisa se dá no projeto da unidade privativa do edifício de apartamentos, ou seja, o espaço interno da moradia. O trabalho está inserido no contexto da cidade de Londrina-PR e busca levantar junto aos usuários idosos suas percepções do ambiente habitacional. Para se aproximar do usuário idoso e extrair dele informações relevantes sobre o apartamento, faz-se necessária a utilização de instrumentos facilitadores para este grupo específico. Nesse sentido, Florio, Segall e Araújo (2007) apontam que as avaliações com modelos físicos têm como um dos aspectos mais significativos seu caráter instrumental para a reflexão, não apenas sobre a criação em si, mas também para desencadear ações cognitivas, experimentações que possam contribuir para o desenvolvimento de habilidades, competências e pensamento crítico.

O crescimento dessa faixa da população pode indicar uma nova demanda por habitações adequadas a esse grupo, sendo que os resultados obtidos em analises previas das suas necessidades, são chamadas de Avaliações Pré-Projeto. Esses procedimentos podem utilizar as simulações com o uso do modelo tridimensional, que buscam auxiliar na identificação dos requisitos ou demandas dos usuários idosos para, assim, poder gerar futuras recomendações projetuais.

\section{A CONSTRUÇÃO DO MODELO DE SIMULAÇÃO}

A construção do modelo utilizado foi baseada em um modelo prévio proposto por Imai (2009), com flexibilidade dos ambientes que utiliza peças que se expandem ou retraem, permitindo aumentar ou diminuir os espaços de acordo com a necessidade dos entrevistados. O modelo também procurou representar todas as características e os dimensionamentos de paredes, aberturas, revestimentos e outros materiais de acabamento, equipamentos e utensílios utilizados dentro da dinâmica do uso da habitação e até mesmo equipamentos para pessoas com mobilidade reduzida, como cadeiras de rodas e andadores (Figura 1). Esse modelo foi utilizado em algumas pesquisas com diferentes objetivos, porém com o foco em ambientes habitacionais (AZUMA 2016; ZALITE, 2016). 
Figura 1 - Mobiliário, objetos e equipamentos utilizados na simulação

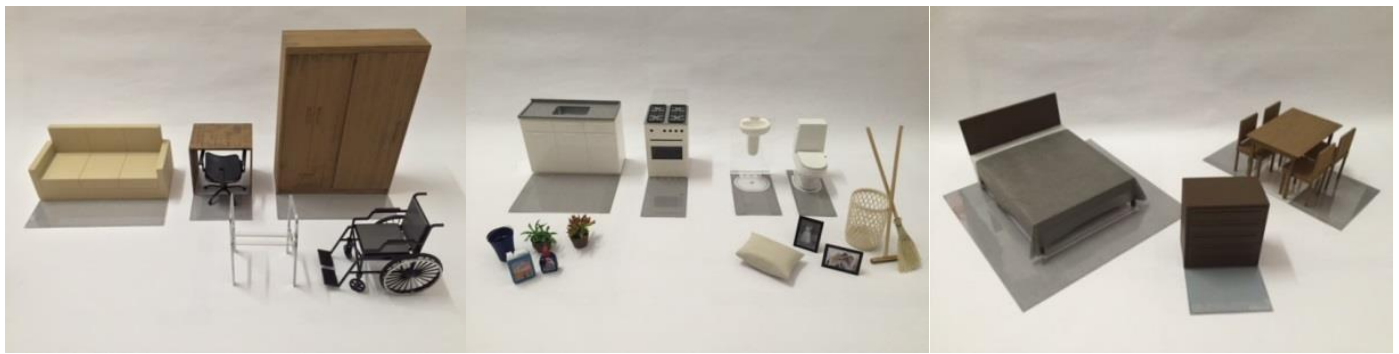

Fonte: Autores (2016).

A escala proposta de 1:10 foi empregada com o intuito de permitir que os usuários pudessem manipular os objetos e visualizar os espaços circulando em torno do modelo e utilizando suas mãos internamente no protótipo para realizar a simulação. Essa escala foi identificada como um limite de dimensões para a realização dessas atividades, pois qualquer tamanho maior criaria dificuldades a essa manipulação. Assim, mediante a analogia com o ambiente real que o modelo tridimensional proporciona, em um instrumento ampliado, objetiva que o usuário idoso, que em muitos casos possui uma perda de sua capacidade cognitiva ou visual, compreenda melhor o projeto da habitação. Esse artefato é uma evolução de um modelo utilizado em pesquisa anterior (IMAI, 2009) que utilizou a escala 1:20. Em virtude da identificação da dificuldade em interpretar alguns aspectos ambientais como circulações e dimensionamentos buscou-se ampliar ao máximo o modelo para auxiliar na compreensão espacial. Os móveis e equipamentos possuem dimensionamentos mínimos recomendados para Habitação Social nos moldes do Programa Minha Casa Minha Vida.

\section{ABORDAGEM JUNTO AO USUÁRIO}

Diversas pesquisas anteriores sobre idosos e suas necessidades em geral e nas habitações Bestetti (2006); Mendes e Corte (2009); Lorenzetti e Mulfarth (2014); Wilmorth, Sliwinski e Mogle (2012), indicam que se devem considerar as barreiras arquitetônicas, as circulações e a orientação espacial entre outros itens relacionados ao espaço privativo da habitação. Portanto, os diferentes resultados foram organizados no sentido de possibilitar a integração de exemplos complementando as abordagens anteriores (Quadro 1).

Quadro 1 - Síntese de experiências em habitação voltadas ao usuário idoso

\begin{tabular}{|c|c|c|c|c|}
\hline \multicolumn{5}{|c|}{ EXPERIÊNCIAS NACIONAIS } \\
\hline Autor & Ano & Resumo da pesquisa & $\begin{array}{l}\text { Contribuição para o } \\
\text { delineamento da simulação } \\
\text { da pesquisa atual }\end{array}$ & $\begin{array}{l}\text { Diretrizes para a } \\
\text { pesquisa atual }\end{array}$ \\
\hline Barros & 2000 & $\begin{array}{l}\text { 1. Recomendações de diretrizes para o espaço } \\
\text { físico do idoso; } \\
\text { 2. Dimensionamento do espaço; } \\
\text { 3. Mobiliário/lluminação; } \\
\text { 4. Tendência à automação. }\end{array}$ & $\begin{array}{l}\text { Exemplos de adaptações } \\
\text { físicas no espaço após a } \\
\text { ocupação. }\end{array}$ & \multirow{2}{*}{$\begin{array}{l}\text { Informações } \\
\text { teóricas para } \\
\text { fundamentar a } \\
\text { investigação do } \\
\text { espaço pelo modelo } \\
\text { físico. }\end{array}$} \\
\hline Bernardo & 2005 & $\begin{array}{l}\text { 1. Tempo na moradia; } \\
\text { 2. Tipo de moradia; } \\
\text { 3. Intervenções no espaço habitado. }\end{array}$ & $\begin{array}{l}\text { Exemplos de adaptações } \\
\text { físicas no espaço após a } \\
\text { ocupação. }\end{array}$ & \\
\hline Bestetti & 2006 & $\begin{array}{l}\text { 1. Considerações Espaciais; } \\
\text { 2. Barreiras Arquitetônicas; } \\
\text { 3. Condições Ambientais; } \\
\text { 4. Revestimentos; } \\
\text { 5. Condições de manutenção; } \\
\text { 6. Aspectos psicodinâmicos; } \\
\text { 7. Aspectos Tecnológicos. }\end{array}$ & $\begin{array}{l}\text { Indicação de itens a se } \\
\text { considerar em pesquisas de } \\
\text { espaços voltados ao usuário } \\
\text { idoso. }\end{array}$ & $\begin{array}{l}\text { Itens a se investigar } \\
\text { com a Ferramenta } \\
\text { Simulação. }\end{array}$ \\
\hline $\begin{array}{l}\text { Mendes e } \\
\text { Côrte }\end{array}$ & 2009 & $\begin{array}{l}\text { 1. Adequação física do espaço do apartamento } \\
\text { para o usuário idoso; } \\
\text { 2. Acréscimo de } 11,86 \mathrm{~m}^{2}\end{array}$ & $\begin{array}{l}\text { Dado relevante que aponta } \\
\text { solução a problemas } \\
\text { levantados em pesquisas } \\
\text { anteriores. }\end{array}$ & \multirow{2}{*}{$\begin{array}{l}\text { Itens a se investigar } \\
\text { com a Ferramenta } \\
\text { Simulação. }\end{array}$} \\
\hline $\begin{array}{l}\text { Lorenzetti } \\
\text { e Mulfarth }\end{array}$ & 2014 & $\begin{array}{l}\text { 1. Avaliação ergonômica de apartamentos; } \\
\text { 2. Circulações; } \\
\text { 3. Escaadas e transições entre pavimentos; } \\
\text { 4. Avaliação das áreas de serviços dos } \\
\text { apartamentos. }\end{array}$ & $\begin{array}{l}\text { Indicação de itens a se } \\
\text { considerar em pesquisas de } \\
\text { espaços voltados ao usuário } \\
\text { idoso e exemplos de } \\
\text { adaptações físicas no espaço } \\
\text { após a ocupação. }\end{array}$ & \\
\hline
\end{tabular}




\begin{tabular}{|c|c|c|c|c|}
\hline $\begin{array}{l}\text { Brondani, } \\
\text { Espadinha } \\
\text { e Santos }\end{array}$ & 2014 & $\begin{array}{l}\text { 1. Criar uma ferramenta (Protocolo) para } \\
\text { identificação das condições de uso dos ambientes } \\
\text { por idosos; } \\
\text { 2. Orientação espacial; } \\
\text { 3. Circulações; } \\
\text { 4. Identificação dos ambientes, cores e texturas; } \\
\text { 5. Dimensão e posicionamento das aberturas. }\end{array}$ & $\begin{array}{l}\text { Indicação de itens a se } \\
\text { considerar em pesquisas de } \\
\text { espaços voltados ao usuário } \\
\text { idoso. }\end{array}$ & $\begin{array}{l}\text { Informações } \\
\text { teóricas para } \\
\text { fundamentar a } \\
\text { investigação do } \\
\text { espaço pelo modelo } \\
\text { físico. }\end{array}$ \\
\hline \multicolumn{5}{|c|}{ EXPERIÊNCIAS INTERNACIONAIS } \\
\hline $\begin{array}{l}\text { Houben e } \\
\text { Voordt }\end{array}$ & 1993 & $\begin{array}{l}\text { 1. Estudo de habitação coletiva para idosos; } \\
\text { 2. Crítica por parte do usuário em relação aos } \\
\text { cuidados em grupo e ao dimensionamento da } \\
\text { habitação (cerca de } 30,00 \mathrm{~m}^{2} \text { ) }\end{array}$ & $\begin{array}{l}\text { Opinião do usuário sobre o } \\
\text { espaço construído e percepção } \\
\text { sobre a habitação coletiva para } \\
\text { idosos. }\end{array}$ & \multirow{3}{*}{$\begin{array}{l}\text { Informações } \\
\text { teóricas para } \\
\text { fundamentar a } \\
\text { investigação do } \\
\text { espaço pelo modelo } \\
\text { físico. }\end{array}$} \\
\hline $\begin{array}{l}\text { Rodwin e } \\
\text { Gusmano }\end{array}$ & 2006 & $\begin{array}{l}\text { 1.Idosos norte-americanos e seus grupos; } \\
\text { 2.Apontamentos sobre a relação dos idosos } \\
\text { americanos e o uso de escadas. }\end{array}$ & \multirow{2}{*}{$\begin{array}{l}\text { Percepção sobre a realidade } \\
\text { dos idosos em outras culturas. }\end{array}$} & \\
\hline Ujikawa & 2010 & $\begin{array}{l}\text { 1. Dados sobre a tendência no mundo de idosos } \\
\text { viverem sozinhos; }\end{array}$ & & \\
\hline $\begin{array}{l}\text { Wilmoth, } \\
\text { Sliwinski e } \\
\text { Mogle }\end{array}$ & 2012 & $\begin{array}{l}\text { 1. Acontecimentos de cotidiano para a avaliação } \\
\text { de atividades físicas diárias, sintomas físicos, } \\
\text { humor e experiências estressantes em idosos } \\
\text { norte-americanos; } \\
\text { 2. Dificuldade dos idosos em realizar tarefas } \\
\text { diárias; } \\
\text { 3. Recomendação do programa de necessidades } \\
\text { mínimas para a habitação de idosos. }\end{array}$ & $\begin{array}{l}\text { Indicação de itens a se } \\
\text { considerar em pesquisas de } \\
\text { espaços voltados ao usuário } \\
\text { idoso e exemplos de } \\
\text { adaptações físicas no espaço } \\
\text { após a ocupação. }\end{array}$ & $\begin{array}{l}\text { Itens a se investigar } \\
\text { com a Ferramenta } \\
\text { Simulação. }\end{array}$ \\
\hline
\end{tabular}

Fonte: Elaborado pelo autor (2016).

\section{MÉTODO PARA A APLICAÇÃO DA PESQUISA}

A adoção da amostra (22 pessoas) se deveu à disponibilidade de entrevistados que tivessem idade superior a 60 anos em participar desta pesquisa no período disponível para sua realização. A pesquisa foi desenvolvida junta a esses usuários idosos no período de fevereiro de 2016 em um Centro de Convivência para idosos localizado na região pesquisada. Todos os procedimentos foram explicados aos entrevistados e aqueles que manifestaram interesse em participar, de forma espontânea, fizeram uma inscrição prévia e em horários agendados. Os dados coletados foram analisados de forma qualitativa em relação a todo o procedimento, incluindo os registros verbais, fotográficos e de formulários em formato de questionário e de roteiros de simulação. Os aspectos abordados nos instrumentos de coleta de informações envolviam a identificação do perfil dos respondentes, a demanda e preferência em relação ao mobiliário, o posicionamento e dimensionamento das aberturas (portas e janelas), o dimensionamento dos ambientes e a acessibilidade interna na moradia, utilizando modelos de referência como a escala humana, o andador e a cadeira de rodas. Por fim, foram avaliados a ferramenta e o processo de simulação com o modelo tridimensional.

Esses aspectos tiveram como objetivo conhecer melhor a realidade dos respondentes, fazendo com que 0 processo de simulação buscasse de certa maneira, uma imersão em seu quotidiano. As entrevistas tiveram uma duração média de 21 minutos, sendo gravadas, fotografadas e, posteriormente, transcritas e tabuladas. A equipe de pesquisa era composta por um entrevistador que se comunicava com os idosos e dois pesquisadores auxiliares que fotografavam, gravavam e registravam os dados coletados. Foram coletadas informações sobre características pessoais dos entrevistados, aspectos de demanda espacial e de necessidades individuais, que serão descritas a seguir.

\section{O projeto para a Simulação}

Com a finalidade de definir o projeto para aplicar a simulação, realizou-se uma pesquisa de todos os empreendimentos residenciais destinados à classe média, disponíveis nos sites das principais construtoras de região, levantando as plantas dos edifícios em lançamento, em construção e os que haviam sido entregues no ano de $2016^{2}$.

No total, foram identificados 69 tipos de plantas disponíveis de 7 construtoras atuantes no mercado, com área útil entre $37,00 \mathrm{~m}^{2}$ (área mínima encontrada) e $91,00 \mathrm{~m}^{2}$ (área que abriga o programa de três dormitórios, com uma suíte,). No levantamento, 07 empreendimentos cujas informações não eram suficientes para seu completo entendimento foram descartados.

A área média dos apartamentos é de $67,33 \mathrm{~m}^{2}$, e a maioria apresenta 3 dormitórios, com uma suíte. A varanda com churrasqueira é um item que aparece em boa parte delas, sendo que algumas apresentam conexão com a área de serviço/cozinha e, também, espaço para a condensadora de ar-condicionado, e 
outras apresentam espaços como closet na suíte e lajes técnicas separadas para a instalação das condensadoras. As paredes do modelo eram presentadas na cor branca, com um piso branco em uma malha quadriculada com portas em madeira e janelas metálicas pré-fabricadas similares às disponíveis no mercado.

Em um estudo-piloto aplicado previamente para auxiliar na delimitação da pesquisa (IMAI et al., 2015), identificou-se que nenhum dos participantes desse estudo utilizou todos os 3 dormitórios, sendo uma suíte, em suas simulações de mobilidade. Assim, para a pesquisa relatada neste artigo, definiu-se um novo projeto derivado do estudo-piloto, com área útil de 64,56 $\mathrm{m}^{2}$, contendo apenas 2 dormitórios $\left(7,80 \mathrm{~m}^{2}\right.$ e 9,69 $\left.\mathrm{m}^{2}\right)$, com uma suíte. A área de serviço $\left(2,08 \mathrm{~m}^{2}\right)$ e a cozinha $\left(5,12 \mathrm{~m}^{2}\right)$ são integradas, permitindo uma conexão visual com a sala por meio de uma parede em meia altura. A sala por sua vez possui uma conexão com uma varanda $\left(3,00 \mathrm{~m}^{2}\right)$. É importante ressaltar que a área total do projeto, nesse caso, não foi fundamentada em algum recorte social.

Para desenvolver o projeto do apartamento simulado, observaram-se as plantas coletadas e a partir delas, foi proposto um modelo (Figura 2), que tem como intenção apenas ser o objeto capaz de captar, por meio da simulação, os requisitos de usuários idosos. Esse modelo não era de nenhum empreendimento especifico, mas um projeto com um desenho que buscou ser o mais representativo da maioria dos empreendimentos. A partir dos resultados obtidos no estudo-piloto, principalmente no que diz respeito ao tempo de aplicação da pesquisa, foi proposto um leiaute do mobiliário previamente montado no modelo, buscando o melhor aproveitamento dos espaços e a dimensão mínima para as circulações entre eles; cada móvel possui, em sua base, uma área mínima para circulação ou execução das atividades (IMAI, 2009), que serve como referência para o usuário no momento da simulação.

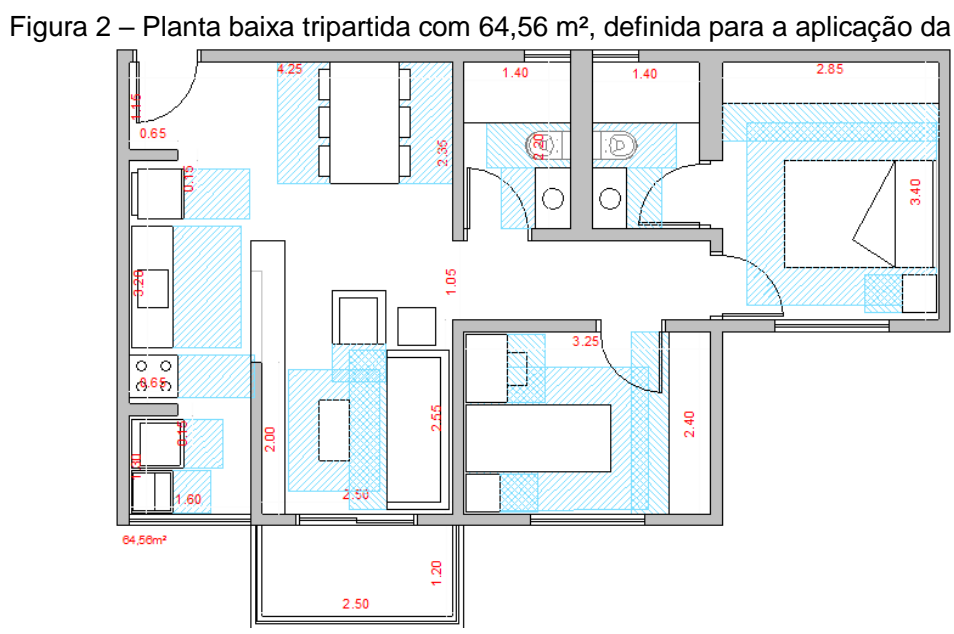

Fonte: Elaborado pelo autor (2016) com base em modelos de referência encontrados na pesquisa de empreendimentos locais.

\section{Aplicação da Simulação e Entrevista}

Para a aplicação da simulação, elaborou-se um protocolo de aplicação que, além de organizar os procedimentos da pesquisa, orienta previamente os pesquisadores em relação à montagem do modelo e à abordagem junto ao usuário.

Inicialmente, foi explicada a atividade de simulação a cada participante citando os objetivos e a importância de sua participação. Em sequência, foi apresentado o modelo tridimensional que estava com o mobiliário, equipamentos, utensílios e aberturas sugeridas pelo projeto. A apresentação do modelo previamente montado teve como intenção reduzir o tempo da aplicação, uma vez que o usuário poderia analisar o leiaute proposto e adicionar ou retirar alguns itens de mobiliário e ou reorganizar o leiaute para adequar suas necessidades.

Assim, em relação a montagem do modelo foram feitos os seguintes questionamentos aos entrevistados: (1) se o mobiliário presente no projeto era ou não suficiente para suas necessidades, se gostaria de adicionar ou retirar algo e o porquê; (2) se o modelo e a posição das aberturas no projeto são ou não suficientes para suas necessidades e se gostaria de adicionar, retirar ou substituir algo e o porquê.

Com a conclusão da montagem do modelo de acordo com as indicações de cada entrevistado, iniciou-se a atividade de simulação de uso dos ambientes. O primeiro item verificado foi a acessibilidade com questões 
sobre o deslocamento nos espaços internos da moradia. Em seguida, o entrevistado foi convidado a simular o mesmo percurso no modelo com o uso da escala humana e, ao final, foi questionado sobre a facilidade ou a dificuldade de se deslocar no espaço.

Posteriormente foram utilizados na simulação equipamentos auxiliares de mobilidade como a cadeira de rodas ou o andador. Ainda que essas pessoas não utilizassem esses equipamentos, foi explicado que a opinião deles era importante para que se conseguissem dados direcionados à melhoria da qualidade do projeto. Convidou-se o entrevistado a simular novamente o percurso descrito no item anterior, agora com o auxílio do andador ou da cadeira de rodas. A escolha de qual auxiliar de mobilidade utilizar ficou a critério do entrevistado.

A próxima etapa da simulação utilizava novamente a escala humana. Solicitou-se aos entrevistados que, movimentando os braços do boneco, colocassem-no na cozinha e na área de serviços e, dessa forma, simulassem alguma atividade diária. Ao fim, o entrevistado era questionado sobre a facilidade ou a dificuldade do uso desse espaço.

Em seguida, buscou-se verificar junto aos usuários a dimensão dos ambientes do apartamento. Eles foram questionados se os espaços dos dormitórios, da sala, da cozinha e da área de serviços atendiam ou não às suas funções, se gostariam de aumentar ou diminuir esses espaços e os motivos das eventuais modificações Também foi questionado aos participantes se, na execução de tarefas diárias, existia alguma dificuldade em relação a: levantar-se, carregar objetos, curvar-se, estender os braços sobre a cabeça, utilizar os dedos para agarrar maçanetas ou puxadores.

Por fim, os entrevistados foram convidados a avaliar a atividade de simulação como ferramenta para o entendimento do projeto. Para tal, solicitou-se a avaliação do modelo em sua contribuição no entendimento do (projeto) apartamento.

\section{RESULTADOS E DISCUSSÃO}

O perfil dos usuários foi identificado com base nas informações coletadas durante a simulação por meio de uma entrevista inicial. O grupo de idosos entrevistados era formado, em sua maioria, por mulheres (18 pessoas do grupo de 22 participantes). A idade média do grupo é de 71,5 anos, sendo que os homens possuíam 79,2 anos, e as mulheres, 69,7 anos.

Com relação à moradia, a maior parte dos entrevistados (14) mora em casas térreas e seu tempo médio de permanência na atual habitação é de 15,2 anos, sendo o menor tempo 3 anos e, o maior tempo, 41 anos. Pouco mais da metade dos entrevistados (12) mora sozinho.

Após a coleta das informações do perfil dos usuários foram iniciadas as simulações que tiveram um tempo médio de 21 minutos. A primeira questão na simulação foi sobre o mobiliário. Em 15 das 22 simulações, houve algum tipo de alteração no mobiliário presente no projeto (Figura 3). As demais (7) afirmaram que 0 leiaute atendia a suas necessidades. Essas variações, além de sugerirem que o leiaute disposto não atendia por completo as demandas desses usuários, também permitem inferir que o poder de decisão, derivado da participação no processo de projeto, reflete em uma liberdade de escolha e uma autonomia incomum para a maioria dos participantes. Dessa forma, como o projeto original é apresentado como um produto finalizado, parecido com o ofertado pelo mercado imobiliário, é sintomático que a maioria dos participantes opte por realizar modificações. Quando lhes é dado a oportunidade de opinar sobre aspectos da moradia, ainda que em um exercício hipotético, a demanda por expressar suas opiniões é perceptível, pois a não participação nas tomadas de decisão podem acarretar questionamentos sobre o projeto, o que perceptível nesta pesquisa.

O fato de o projeto apresentar apenas 2 dormitórios parece ser satisfatório para a maioria do grupo de entrevistados, possivelmente reflexo da configuração do grupo familiar, que é reduzida nesse grupo, pois a maioria vive sozinha ou acompanhada de apenas mais uma pessoa. 
Figura 3 - Adição de mobiliário ao leiaute proposto

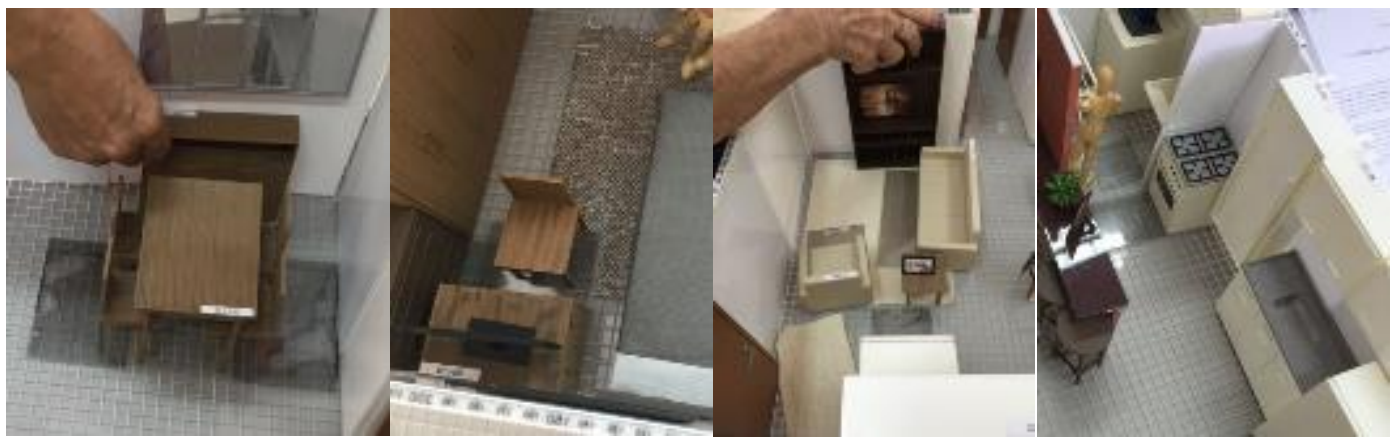

Fonte: Elaborado pelo (2016).

Em alguns desses casos (4 entrevistas) a reorganização dos leiautes demandou o reposicionamento dos ambientes ou a alteração de paredes, como por exemplo a colocação de uma parede para isolar a cozinha da sala. (Figura 4). Observa-se que, em duas situações, os entrevistados comentaram a possibilidade de instalação de um alarme de segurança que pudesse informar a necessidade de socorro para alguém na portaria, por exemplo. Obter esse resultado não era a intenção de nenhum questionamento específico da simulação, mas entende-se que, a partir do momento em que se leva o usuário a refletir sobre algo observando o modelo tridimensional, é possível ele se imaginar em outras situações e, de maneira voluntária, contribuir com informações que julgam importantes. A simulação demonstrou um potencial significativo na coleta de dados qualitativos de forma espontânea.

Figura 4 - Reorganização do leiaute pelos entrevistados

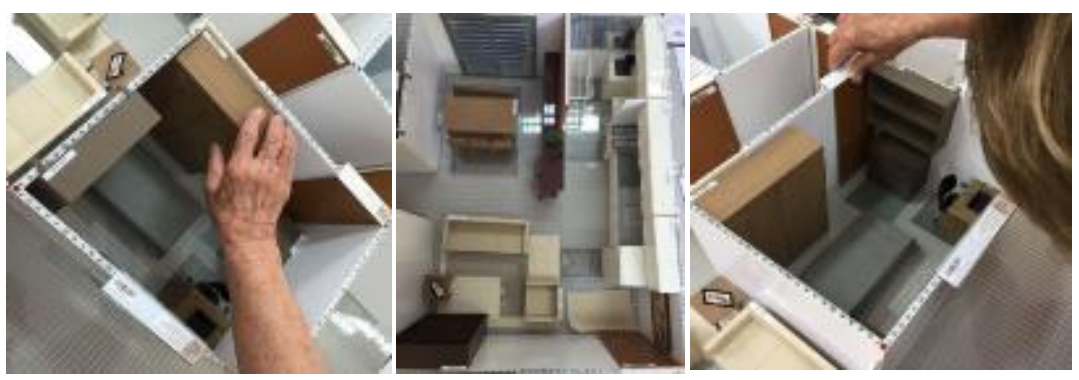

Fonte: Elaborado pelo autor (2016).

É possível constatar também que, quando os entrevistados são convidados a observar o modelo e a responder a primeira questão em relação ao mobiliário, em alguns casos, acabam expondo suas opiniões relativamente a todo o projeto e chegam até a descrever situações em sua própria habitação para ilustrar sua opinião. As descrições, na maioria das vezes, carregam uma riqueza de detalhes sobre a qual é possível entender a rotina e as possíveis necessidades dos entrevistados, como nesse exemplo:

Pergunta: O mobiliário presente no projeto/modelo é ou não suficiente para as suas necessidades, Gostaria de adicionar ou retirar algo? Por quê?

Respondente: Eu termino meu serviço na cozinha e vou sentar no sofá assistir minha TV e fazer o meu crochê, lá eu fico um tempão, até ficar com fome e ir na cozinha preparar um lanchinho. Gosto de cuidar das minhas flores, das plantas... eu gosto muito de plantas, tenho muitos vasos...

Observações específicas sobre as aberturas surgiram de 4 entrevistados durante as simulações: um deles comentou que as portas poderiam ser construídas com algum material que permitisse o contato visual de um espaço para o outro - uma solução para segurança psicológica em caso de queda ou pânico. $O$ segundo comentou que as janelas do tipo veneziana são ruins para limpeza, porém necessárias para o bloqueio da luz solar. O terceiro usuário recomendou que janelas de correr com quatro folhas são mais fáceis de manusear em relação às de duas folhas. O último usuário afirmou que as portas deveriam ter a largura mínima para a passagem de equipamentos auxiliares de locomoção. Algumas dessas informações são (ou pelo menos deveriam ser) relativamente conhecidas nas boas práticas de projeto. A explicitação 
dessas observações pelos entrevistados indica o quanto esses pequenos aspectos podem representar inadequações que geram incômodos aos usuários.

Dessa forma, considerando a opinião dos usuários sobre as aberturas no projeto simulado, percebe-se que existe uma preocupação, ainda restrita (6 entrevistados), sobre a ventilação e a iluminação dos espaços dentro da habitação, principalmente na sala - onde há o maior tempo de permanência da maioria do grupo. A manutenção das aberturas no que diz respeito à limpeza e ao manuseio delas também são fatores relatados pela mesma parcela desses idosos.

Pensar na segurança psicológica em caso de queda ou pânico e ainda na manutenção de alguns elementos da casa pode ser reflexo, entre outros motivos, do grupo familiar pequeno, no qual a maioria vive sozinha ou acompanhada por apenas uma pessoa e, possivelmente, fazem a própria limpeza da casa. Por algumas dessas pessoas já apresentarem certa redução na mobilidade e no manuseio de objetos, os sistemas de aberturas que demandam mais motricidade são desfavoráveis no uso diário para o idoso.

Assim que as questões referentes à montagem do modelo foram concluídas por parte dos entrevistados, iniciou-se a simulação dos itens de acessibilidade. Para realizar essa atividade, inicialmente, os entrevistados foram questionados sobre qual seria o percurso mais frequente dentro de sua casa. Metade do grupo (11 entrevistados) respondeu que se desloca mais da cozinha para a sala ou vice-versa.

Porém, o fato de a metade dos idosos entrevistados se deslocar dessa forma pode estar relacionado à maioria do grupo ser formada por mulheres que vivem sozinhas ou acompanhadas de mais uma pessoa, necessitando fazer as próprias atividades diárias da casa. Ainda, isso pode estar relacionado a uma opção ou condição de vida ativa por parte dos idosos, mantendo-os independentes até a segunda ordem.

Em seguida, os usuários foram convidados a simular, com o uso da escala humana, o percurso que definiram anteriormente. Alguns iniciaram o percurso pela sala de estar ou jantar (porta de acesso), alguns, pela cozinha, porém todos circularam pela área social, pela cozinha e serviços (Figura 5). Poucos se estenderam para o banheiro e dormitórios, e a varanda fez parte do percurso de apenas um usuário. Ao final, os entrevistados foram questionados sobre a facilidade ou a dificuldade de circular pelo espaço do apartamento com a escala humana.

Figura 5 - Percurso com o uso da escala humana

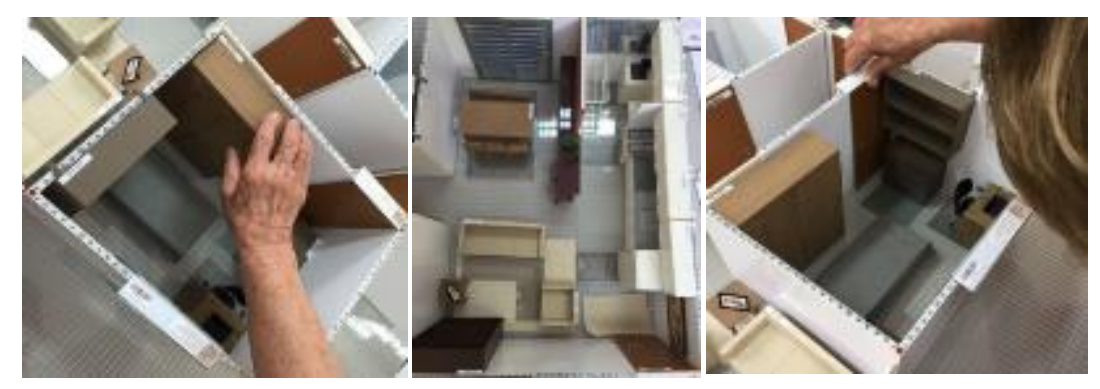

Fonte: Elaborado pelo autor (2016).

Após a simulação com o uso da escala humana, os usuários foram convidados a simular o mesmo percurso com o auxílio do andador ou da cadeira de rodas. Foram doze os idosos que escolheram simular o percurso com o uso da cadeira de rodas enquanto nove escolheram o andador e um usuário não opinou.

Dos onze usuários que disseram encontrar dificuldade no momento da simulação com os auxiliares de mobilidade, nove retiraram algum mobiliário para permitir a conclusão do percurso (Figuras 6 e 7). Para alguns usuários (cinco), adjetivos e expressões como "apertado", "bem apertadinho" e "não pode ter tapete" resumiram essa simulação. Outros três entrevistados afirmaram que o percurso com os auxiliares foi fácil, porém um deles esbarrou em um móvel. Por fim, três idosos simularam o percurso, mas não exprimiram sua opinião. 


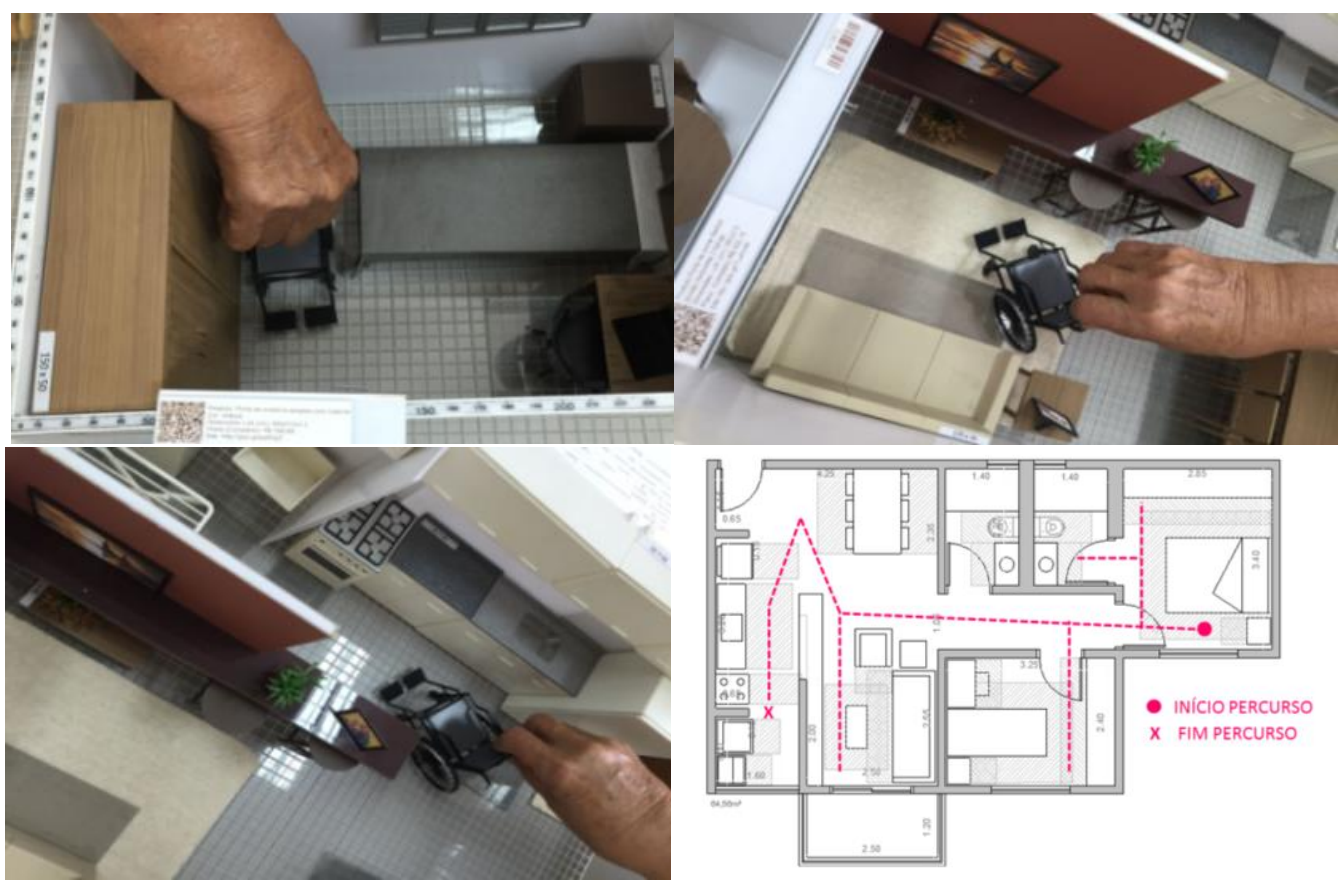

Fonte: Elaborado pelo autor (2016)

Figura 7 - Percurso com auxílio do andador
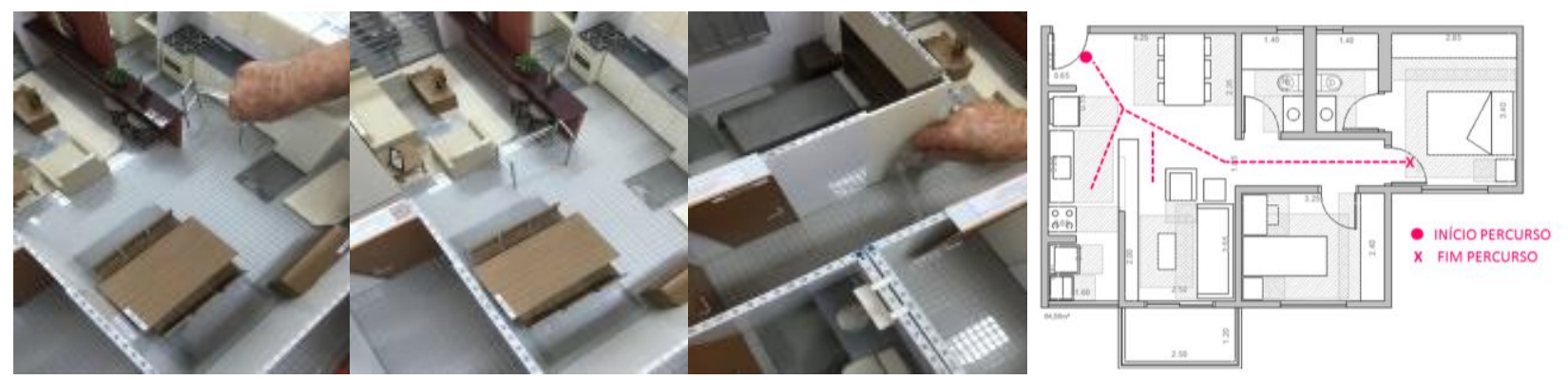

Fonte: Elaborado pelo autor (2016).

Assim, para concluir as simulações e questões referentes à acessibilidade dentro do apartamento, os idosos foram convidados novamente a utilizar a escala humana para verificar se achavam fácil ou difícil a execução de tarefas diárias nas áreas de serviço e da cozinha. Eles foram orientados sobre a possibilidade de movimentação que a escala humana permitia, simulando, assim, atividades como lavar louça, abrir armários, lavar e estender roupas, entre outros.

Os entrevistados foram questionados: "O boneco que utilizamos tem os braços articulados. Podemos movimentá-los simulando alguma atividade, Vamos experimentar? Coloque-o na Cozinha e na Área de Serviço e imagine alguma atividade. Você acha que é fácil ou difícil o uso deste espaço? Por quê?"

Poucos usuários que simularam (seis) acharam fácil a atividade de manuseio dos espaços da cozinha e serviços (Figura 8). Apenas dois usuários simularam e sentiram a necessidade de retirar o varal de piso para melhorar a circulação na área de serviço. Outros oito usuários fizeram comentários para validar suas respostas, entre elas: "Estou acostumada com cozinha pequena..."; "As portas dos armários precisam ser de correr, para não trombar..."; "O tanque precisa estar de acordo com a altura de cada pessoa..." e "Os armários precisam ser mais baixos..." Os demais entrevistados (seis) não simularam a atividade, portanto não opinaram. 
Figura 8 - Simulação da atividade com o boneco articulado

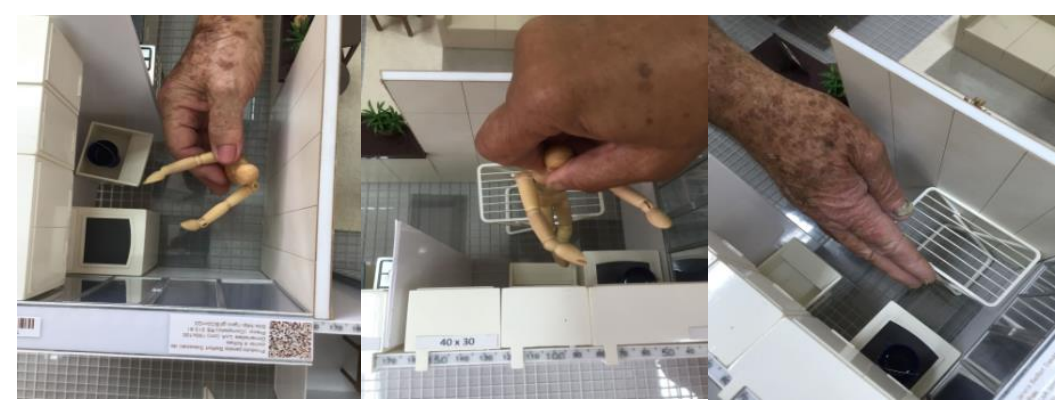

Fonte: Elaborado pelo autor (2016).

Ainda que o modelo tridimensional tenha restrições quanto à sua construção, como as portas dos armários não abrirem, por exemplo, isso não foi empecilho para que alguns dos entrevistados refletissem sobre aquele espaço e suas necessidades.

A forma como os idosos pensam a respeito de sua segurança espacial dentro do apartamento está focada em aspectos comportamentais arraigados. Sobre a relação dos idosos com o uso de tapetes, por exemplo, percebe-se que seu uso está relacionado a uma questão estética pessoal - de conforto visual e térmico. É possível perceber também que, em alguns casos, é maneira de minimizar a manutenção da limpeza diária, como no caso da utilização na cozinha - próximo da pia - e no banheiro, evitando os respingos de água. A maioria dos idosos tem consciência de que o uso de tapetes pode, em algum momento, afetar a segurança no deslocamento dentro da habitação. Ainda assim, apesar de alguns terem consciência das restrições de mobilidade, existe uma percepção de que é uma condição não existente atualmente e que apenas no futuro isso Ihes prejudicará. A percepção geral é a de eles ainda não se sentem "velhos" e que as suas eventuais limitações não são significativas.

Olhando para o modelo, os idosos foram convidados a avaliar se determinado espaço atendia ou não às funções necessárias e se o mesmo deveria ser alterado. O dormitório e a suíte avaliados possuíam áreas de 7,80 $\mathrm{m}^{2}$ e 9,69 $\mathrm{m}^{2}$, respectivamente. Para quatorze dos vinte e dois idosos, os dormitórios atendiam às funções de que necessitavam; apenas um reorganizou o mobiliário na suíte para afirmar que o espaço atendia às suas necessidades. Para seis entrevistados, os dormitórios não atendiam às necessidades e precisavam ser aumentados. Apenas 1 idoso não opinou sobre essa questão.

É importante destacar que em muitos casos os dormitórios não eram prioridades no dia a dia, e isso ficou mais claro quando se compara esse questionamento aos resultados obtidos, no qual o percurso mais recorrente para o grupo está entre a cozinha e a sala.

A cozinha e a área de serviço, com 5,12 $\mathrm{m}^{2}$ e 2,08 $\mathrm{m}^{2}$, respectivamente, também foram alvos de questionamento sobre seu dimensionamento. As opiniões ficaram divididas, pois 10 entrevistados afirmam que a cozinha e a área de serviço satisfaziam às suas necessidades, e 9 declaram que a cozinha e a área de serviço precisavam ser aumentadas. Apenas um usuário precisou reorganizar o leiaute da cozinha para afirmar a satisfação com o espaço, e os 3 entrevistados restantes não opinaram.

O resultado acima pode estar relacionado ao fato de que parte significante (14 entrevistados) do grupo respondente não mora em apartamentos. Sabe-se que as cozinhas dos apartamentos, se comparadas com as cozinhas de casas térreas, são, na maioria dos casos, significativamente menores. Dessa forma, os usuários possivelmente criaram um modelo de comparação com a sua situação atual e as necessidades e os desejos que demandem mais espaço como, por exemplo, ter uma mesa na cozinha.

Algumas das justificativas para o aumento desses espaços estão relacionadas com a possibilidade de utilização dos auxiliadores de locomoção - andador e cadeira de rodas. Faz-se pertinente comentar que parte dos usuários elogiaram a disposição da cozinha em linha e sua proximidade com a área de serviços, pois, de acordo com eles, isso facilita o trabalho no dia a dia, criando a possibilidade de se trabalhar em duas ou mais atividades ao mesmo tempo, nos espaços distintos.

Acredita-se que o fato de os entrevistados não realizarem modificações no dimensionamento dos espaços, possa estar relacionado ao modelo ser claro para o usuário quanto ao espaço que representa. Ainda que, em diversas situações, o dimensionamento dos ambientes foi considerado insuficiente, esse aspecto foi apenas identificado e relatado pelos entrevistados. As modificações de posicionamento de paredes, com ampliação ou diminuição dos espaços, aumentam o tempo da atividade. O maior tempo de simulação pode 
acarretar cansaço para esses usuários que optam por ter maior objetividade na identificação dos problemas e não necessariamente na sua solução.

Em alguns poucos casos (4 entrevistados) foram relatados problemas de locomoção e de execução de atividades corriqueiras, como dificuldades ao levantar, pegar peso ou agachar. Um entrevistado complementou afirmando que maçanetas redondas dificultam a empunhadura da mão. A maior parte afirmou não haver maiores dificuldades nas locomoções internas na moradia e nas atividades diárias.

No geral, o grupo de idosos entrevistados apresenta-se ativo no seu cotidiano. Dessa forma, questionar o usuário sobre essas atividades permite que ele contribua com informações relevantes. Nesse caso, a presença do modelo tridimensional colabora para essa questão. Um exemplo interessante é quando o usuário observou o modelo, ainda que limitado por sua escala reduzida, e conseguiu perceber um aspecto sobre a maçaneta da porta, permitindo lembrar de algo que considerava importante.

Ao final de toda a entrevista, os participantes foram convidados a atribuir uma nota para quanto o modelo contribuiu a fim de que eles compreendessem o projeto do apartamento. A maioria dos idosos (13) atribuiu nota máxima ao modelo tridimensional apresentado (Gráfico 01), complementado por comentários que ilustravam sua satisfação em relação ao entendimento do projeto, como no exemplo abaixo:

Pergunta: Gostaríamos que você atribuísse uma nota para o quanto essa maquete contribuiu para o entendimento do projeto (apartamento)? Sendo 1 para o baixo entendimento e 10 para o máximo entendimento.

Respondente: Ela me fez refletir sobre as dificuldades que a gente tem. Não moro em apartamento e nem sei morar, gosto muito de plantas e jardins. Fez-me refletir, até para eu escolher, se eu for morar, eu tenho que ver algumas coisas... (...) A maquete dá prá ver melhor do que na planta...

Gráfico 01 - Nota atribuída pelos idosos sobre a Simulação e o Modelo Tridimensional

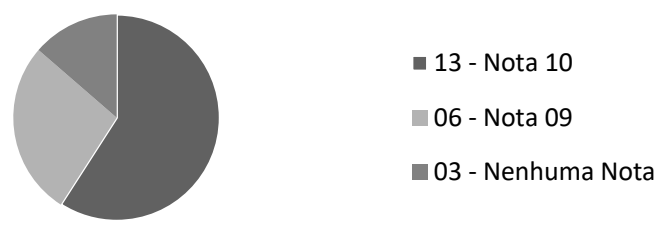

Fonte: Elaborado pelo autor (2016).

Outros comentários estão diretamente ligados à dimensão espacial e não diretamente ao modelo: "Eu achei pequeno esses quartos, a sala... e banheiro também..." Apesar de não ser uma afirmação diretamente sobre o modelo, o usuário indica que esta percepção sobre o espaço foi decorrente da representação tridimensional. Neste sentido, deve-se investigar se, para este perfil de usuários, a representação tridimensional física aplicada conjuntamente com a digital pode ampliar esta compreensão (autor, 2016). Por fim, os participantes foram solicitados a atribuir pontos positivos ou negativos referentes à atividade de simulação com o modelo tridimensional. As informações coletadas tiveram a participação da maioria dos entrevistados (20 casos) e indicam que, muitas vezes, o instrumento não é compreendido como uma forma de representação de um ambiente projetado, mas sim confunde-se com o próprio espaço. Em alguns casos as pessoas focam mais em aspectos do projeto do que em avaliar se o modelo é uma forma de representação compreensível, como exemplificado na transcrição abaixo:

Pergunta: Você poderia apontar um ou mais pontos positivos ou negativos sobre a atividade com o uso da maquete?

Respondente: Eu não gosto muito de área de serviço junto com a cozinha, acho que pega cheiro nas roupas estendidas no varal... Sobre o modelo, acho que está tranquilo!

As afirmações provenientes da questão aberta feita com os idosos revelaram o entendimento espacial que 0 modelo tridimensional proporcionou a essas pessoas durante a atividade da simulação. O envolvimento dos usuários com a atividade permitiu que eles se sentissem confortáveis para sugerir melhorias no próprio modelo, como, por exemplo, a utilização de portas com vão de passagens para que a simulação se aproximasse ainda mais da realidade:

Respondente: Poderia ter um vão... (sinalizando que as aberturas que simbolizam as portas deveriam ser permeáveis). Eu colocaria porta de verdade aí... Para ela abrir e fechar. $\mathrm{O}$ ponto positivo é que visualiza tudo de maneira pequena, mas bem real... 


\section{CONSIDERAÇÕES FINAIS}

Pode-se considerar que, com as opiniões evidenciadas pelos entrevistados, foi possível identificar um conjunto de necessidades ou idealizações para um apartamento mais próximo à sua realidade. Os idosos em questão indicaram que esse modelo, preferivelmente, pode ser configurado por um programa de necessidades que contemple uma área maior voltada aos espaços de serviço e estar, deixando as áreas íntimas com o estritamente necessário para suas funções de dormir e guardar.

Ainda que a maioria dos usuários indique não ser necessário prever ambientes para uma possível futura utilização de equipamentos auxiliares de mobilidade, quando provocados a pensar e simular o uso dos ambientes nessas condições, há uma reflexão sobre a importância desse aspecto. O perfil desses usuários idosos indica que são ativos e participam de diversas atividades, inclusive no Centro de Convivência do Idoso no qual a pesquisa foi aplicada. Aplicar esse tipo de trabalho em um ambiente conhecido, aos idosos, em sua zona de conforto, contribuiu para que eles não tivessem receio em participar e emitir suas informações.

Em relação às atividades simuladas com a movimentação da figura humana, notadamente nos movimentos dos braços do boneco e no uso de tecnologias assistivas como o andador e a cadeira de rodas, as limitações são evidentes e devem ser levadas em consideração na avaliação e análise ambiental. Toda simulação, e em especial em modelos reduzidos, traz uma evidente perda de precisão das análises em função de seu caráter reducionista. Essa ressalva deve ser levada em consideração nos resultados pois, além da amostra ser reduzida, a percepção de que os espaços são diminutos podem sofrer influência de própria dimensão reduzida do instrumento de simulação. Recomenda-se, para procedimentos futuros, a aplicação em uma amostra mais ampla e representativa e a simulação em ambientes em escala real comparativamente à escala reduzida baseado nos padrões das áreas de aproximação recomendadas pela norma NBR 9050.

Eventualmente seria necessário investigar qual seria a proporção desse grupo em relação ao universo de idosos. Para esses entrevistados, no entanto, existe uma convicção, ou uma preconcepção, de que ele não é necessariamente idoso, e sim outras pessoas o são, sendo o termo entendido como algo pejorativo que indica debilidade. A simulação com o modelo representou a reflexão de um aspecto que muitas vezes não se desejava pensar ou antecipar sua discussão, mas que foi objeto de depoimentos espontâneos durante a pesquisa sobre a importância do mesmo e a necessidade planejar o avançar da idade prevendo possíveis limitações.

Ainda, deve-se haver maior atenção às decisões e aos elementos que compõem o projeto e que permitem que os idosos se sintam confortáveis e seguros psicologicamente dentro do apartamento. Os materiais, o desenho e os mecanismos que compõem as aberturas e até mesmo o mobiliário devem ser leves, de manutenção e manuseio fáceis, levando em consideração aspectos de ergonomia e uma possível restrição na motricidade. O Quadro 2, a seguir, tem por objetivo organizar de maneira sistemática os resultados qualitativos referentes aos requisitos identificados pelos usuários por meio da simulação.

Quadro 2 - Quadro-resumo de requisitos identificados pelos usuários por meio da simulação

\begin{tabular}{|c|c|}
\hline \multicolumn{2}{|c|}{ QUADRO-RESUMO DE REQUISITOS IDENTIFICADOS PELOS USUARIOS POR MEIO DA SIMULAÇÃO } \\
\hline ITENS AVALIADOS & REQUISITOS ENCONTRADOS \\
\hline Acessibilidade & $\begin{array}{l}\text { 1- Os espaços devem ser dimensionados e com leiaute coerente para que se possibilite uma } \\
\text { temporária ou futura utilização de equipamentos auxiliares de mobilidade (andador/cadeira de } \\
\text { rodas); } \\
\text { 2- O leiaute da cozinha disposto em "linha" facilita o uso no dia a dia; } \\
\text { 3- A proximidade da cozinha com a área de serviço facilita a circulação do idoso. }\end{array}$ \\
\hline Segurança & $\begin{array}{l}\text { 1- Ainda que a utilização de tapetes seja reconhecidamente perigosa para usuários idosos, } \\
\text { seu uso está relacionado a uma questão comportamental, de estética pessoal e de conforto } \\
\text { térmico do idoso. Também pode ser considerado como uma maneira de minimizar a } \\
\text { manutenção da limpeza diária. } \\
\begin{array}{c}\text { 2- Segurança Psicológica: Visores nas portas e barras de apoios nas áreas de risco como } \\
\text { banheiros e campainhas que possam ser acionadas em caso de pânico. }\end{array}\end{array}$ \\
\hline Eficiência & $\begin{array}{l}\text { 1-Aberturas: Materiais, desenhos e mecanismos que compõem as aberturas devem ser leves, } \\
\text { de manutenção e manuseios fáceis para os idosos; } \\
\text { 2-Mobiliário: As portas dos armários de correr são mais eficientes, pois evitam que os } \\
\text { usuários se esbarrem nas portas quando abertas; } \\
\text { 3-Programa de necessidades: As áreas de serviços e social são as áreas prioritárias para os } \\
\text { usuários idosos; } \\
\text { 4-Conforto Ambiental: Ventilação cruzada e aberturas generosas. }\end{array}$ \\
\hline
\end{tabular}




\begin{tabular}{|l|c|}
\hline & $\begin{array}{c}\text { 1-Mobiliário: Todas as bancadas (tanques, pias da cozinha e banheiros) devem ser } \\
\text { preferencialmente ajustados de acordo com a altura média dos usuários para facilitar as } \\
\text { atividades diárias; }\end{array}$ \\
$\begin{array}{c}\text { Mobilidade e } \\
\text { Autocuidado }\end{array}$ & $\begin{array}{c}\text { 2-Equipamentos: Maçanetas com desenho de empunhadura redondos devem ser evitados, } \\
\text { pois são difíceis de utilizar; }\end{array}$ \\
& $\begin{array}{r}\text { 3-Mobiliário: Puxadores devem ser visualmente aparentes, de fácil empunhadura, porém não } \\
\text { devem ressaltar a superfície do móvel para evitar acidentes. }\end{array}$ \\
\hline
\end{tabular}

Fonte: Elaborado pelo autor (2016).

Na presente pesquisa, a aplicação do estudo-piloto (IMAl et al, 2015) como estratégia para a reformulação dos procedimentos na pesquisa final foi de grande contribuição, pois permitiu testar o que se pretendia simular, além de facilitar a compreensão e ajustar os procedimentos para a aplicação final da pesquisa. Identificou-se, inicialmente, a possibilidade de coletar os requisitos dos usuários idosos com muita riqueza de detalhes, porém a maior questão levantada pelo estudo-piloto foi o tempo de aplicação das simulações que acarretava cansaço aos usuários.

Com isso, para a aplicação final da pesquisa foi reduzida a quantidade de informações coletadas comparativamente ao estudo piloto. Cabe ressaltar que, por mais que o estudo-piloto tenha abordado apenas seis entrevistados, a riqueza das informações alcançadas para cada uma é comparativamente maior do que nas entrevistas finais.

Nesse caso, pode-se afirmar que a relevância dos resultados que envolvem pesquisas com aspectos qualitativos não está diretamente ligada a um amplo universo de pesquisa. É preferível que se dedique mais tempo à exploração de cada indivíduo que componha um universo menor, coletando a maior quantidade de informações com o máximo de detalhes possíveis, do que o contrário, ainda que no caso desta pesquisa 0 fator tempo esteja diretamente relacionado à capacidade física do entrevistado em contribuir com o processo.

Nessa relação, o empenho dos aplicadores no que diz respeito à explicação da importância de se obter essas informações e o ganho da confiança por parte do entrevistado é extremamente importante para que se consiga sucesso neste tipo de pesquisa. A pesquisa com idosos envolve, além dos fatores descritos acima, atenção especial à capacidade de ouvir. As pessoas carregam consigo uma bagagem de experiências, e compartilhá-las permite que se sintam produtivas.

Especificamente em relação ao modelo tridimensional, com os resultados apresentados, é possível identificar que a escala humana é capaz de simular atividades no modelo e levar os usuários à reflexão sobre as ações, e isso fica ainda mais claro quando alguns dos usuários que simularam atividades sugerem possibilidades de readequação desses espaços às suas necessidades. O Quadro 3, a seguir, tem por objetivo organizar de maneira sistemática os resultados qualitativos referentes à avaliação dos procedimentos da pesquisa e do instrumento.

Quadro 3 - Quadro-resumo de avaliação dos procedimentos de pesquisa e do instrumento

\begin{tabular}{|c|c|}
\hline \multicolumn{2}{|c|}{ QUADRO-RESUMO DE AVALIAÇÃO DOS PROCEDIMENTOS DE PESQUISA E DO INSTRUMENTO } \\
\hline ITENS AVALIADOS & RESULTADOS \\
\hline $\begin{array}{c}\text { Fundamentação } \\
\text { teórica }\end{array}$ & $\begin{array}{l}\text { 1- O cruzamento de informações multidisciplinares colaborou a fim de que se chegasse a } \\
\text { diretrizes para a elaboração do protocolo de aplicação da pesquisa. }\end{array}$ \\
\hline Estudo-piloto & $\begin{array}{l}\text { 1- Permitiu testar e compreender o que se pretendia simular, assim podendo ajustar os } \\
\text { procedimentos para a aplicação final da pesquisa; } \\
\text { 2- Questão tempo: a atividade com duração acima de uma hora cansa os usuários; } \\
\text { 3- É preferível que se dedique mais tempo na simulação com cada indivíduo, coletando a } \\
\text { maior quantidade de informações com o máximo de detalhes possíveis, com o devido cuidado } \\
\text { em relação ao conforto físico e pessoal de cada entrevistado. }\end{array}$ \\
\hline $\begin{array}{l}\text { População e Equipe } \\
\text { de aplicação }\end{array}$ & $\begin{array}{l}\text { 1- Aplicar este tipo de trabalho em ambientes habituais aos idosos contribui para que eles não } \\
\text { tenham receio em participar e emitir suas informações; } \\
\text { 2- Uso de equipes para a aplicação, observação e registro da simulação. }\end{array}$ \\
\hline $\begin{array}{l}\text { Modelo } \\
\text { tridimensional }\end{array}$ & $\begin{array}{c}\text { 1- A escala humana cumpre seu papel de referência dentro do modelo, produzindo resultados } \\
\text { que levam os usuários a refletirem sobre suas ações durante a simulação; } \\
\text { 2- O modelo tridimensional construído com riqueza em detalhes auxilia a conexão do } \\
\text { imaginário sobre o idoso com um objeto real por meio ao modelo; } \\
\text { 3- A utilização dos equipamentos auxiliares de mobilidade na escala do modelo é capaz de } \\
\text { envolver os entrevistados na atividade, com um ganho de conhecimento e percepção do } \\
\text { problema; } \\
\begin{array}{c}\text { 4- Utilização de portas e janelas que pudessem abrir e fechar para deixar a simulação mais } \\
\text { realística. }\end{array}\end{array}$ \\
\hline
\end{tabular}

Fonte: Elaborado pelo autor (2016). 
É possível perceber também que a utilização dos auxiliares de mobilidade é capaz de transportar e envolver o usuário ao modelo tridimensional e à atividade. Sem o uso desses elementos que permitem a interação direta do entrevistado com o modelo, possivelmente, algumas questões não teriam respostas tão claras. Contudo, identificou-se que o modelo físico tem a capacidade de encantar as pessoas, principalmente os idosos. No contato com essa ferramenta, eles conseguem expressar sentimentos e opiniões de forma espontânea. Especialmente na manipulação do modelo em escala reduzida, é notório o sentimento de afeto das pessoas pela moradia. Essa projeção de questões afetivas é evidenciada quando provocado a avaliar e eficácia do modelo enquanto instrumento de comunicação do projeto, e mesmo assim manifestam suas opiniões sobre o espaço físico da moradia. O modelo passa a ser um instrumento de imersão no projeto e, por conseguinte, no próprio ambiente que está sendo planejado. Um aspecto metodológico que deve ser ressaltado é o da abordagem a esse perfil de usuário, pois ouvir pacientemente e incentivar a interação e estimular e valorizar a importância da experiência acumulada por décadas favorece o vínculo e confiança e de autonomia do participante.

Como o presente trabalho constituiu um estudo investigativo exploratório sobre idosos e sua moradia, outras pesquisas podem ser sugeridas a partir das discussões iniciadas por este trabalho, Como, por exemplo, relacionar a hierarquização das prioridades dos idosos no apartamento, delimitadas por segmentos de renda e identificar as prioridades dos idosos em relação às áreas comuns dos edifícios de apartamento e investigar os aspectos da segurança psicológica dos idosos no apartamento.

Como descrito nos itens anteriores, acredita-se que segmentar a simulação em assuntos complementares que fazem parte da rotina diária dos idosos pode simplificar e facilitar a coleta de informações e ampliar a compreensão de parte do conjunto de requisitos ou de suas demandas diárias da moradia de forma mais ampla.

A simulação com o uso do modelo tridimensional mostrou-se um instrumento útil na identificação de requisitos e demandas dos usuários, isso pela dinâmica do processo de simulação, permitindo que o modelo possa ser tocado, movimentado e sentido pelas pessoas. Ele também é intuitivo, porque leva a possibilidades de experimentações e, ainda que não previsto inicialmente, envolveu os participantes ao resgatar memórias e sentimentos que as pessoas guardam consigo sobre o que compreendem como "lar".

\section{REFERÊNCIAS}

AZUMA, M. H.; Customização em massa de projeto de habitação de interesse social por meio de modelos fisicos paramétricos. 2016. Tese (Doutorado em Arquitetura, Urbanismo e Tecnologia) - Instituto de Arquitetura e Urbanismo, Universidade de São Paulo, São Carlos, 2016.

BESTETTI, M. L. T. Habitação para idosos. O trabalho do arquiteto, arquitetura e cidade. 2006. 184 f. Tese (Doutorado em Estruturas Ambientais Urbanas) - Faculdade de Arqutietura e Urbanismo - FAU USP, São Paulo, 2006.

FISCHER, Milena. A.; SILVA FILHO, Irênio Gomes da. Desafios de Mobilidade Enfrentados por Idosos em seu Meio. In: V Mostra de Pesquisa da Pós-Graduação - PUCRS, 2010, Porto Alegre. Anais... Porto Alegre: PUCRS, 2010. p. 698712.

FLORIO, W.; SEGALL, M.L.; ARAÚJO, N. S. A Contribuição dos protótipos rápidos no processo de projeto em arquitetura. Graphica, Curitiba, 2007.

FUENTES, F. A. et al. Como moram muitos de nossos velhos? Reflexões sobre um conjunto de visitasa instituições que abrigam pessoas idosas. Caderno Temático Kairós Gerontologia, v. 8, p. 125-153, 2010.

IMAI, C. O processo projetual e a percepção dos usuários: o uso de modelos tridimensionais físicos na elaboração de projetos de habitação social. Ambiente Construído, Porto Alegre, v. 9, n. 2, p. 105-118, 2009.

IMAI, C.; AZUMA, M.; RODRIGUES, R.; ZALITE, M. O modelo tridimensional físico como instrumento de simulação na habitação social. Gestão \& Tecnologia de Projetos, v. 10, n. 2, p. 7-20, 6 nov. 2015.

LORENZETTI, N. M.; MULFARTH, R. C. Avaliação ergonômica das funções e atividades em unidade habitacional de idoso: expectativas e necessidades de conforto, bem estar e autonomia de idosos aptos. In: $V$ Encotro Nacional de Ergonomia do Ambiente Construído, 5., 2014, Rio de Janeiro. Anais... Rio de Janeiro, 2014.

MENDES, F. R.; CÔRTE, B. O ambiente da velhice no país: Por que planejar? Kairós, São Paulo, v. 12, n. 1, p. 197212, 2009.

QUEIROZ, F. D.; TRAMONTANO, M. Apartamentos paulistanos: um olhar sobre a produção privada recente. Ambiente Construído, v. 9, n. 2, 2009. 
VILLA, S. B.; SARAMAGO, R. P.; PIRES, R. G. A Qualidade Espacial e Ambiental de edifícios de apartamentos em cidades médias. In: III Encontro da Associação Nacional de Pesquisa e Pós-graduação em Arquitetura e Urbanismo, 3. 2014, São Paulo. Anais... São Paulo: III ENANPARQ, 2014.

WILMOTH, M. J.; SLIWINSKI, M.; MOGLE, J. Uma sondagem via internet projetada para avaliar a vida diária dos idosos. Sociologias, v. 14, n. 31, p. 120-144, 2012.

ZALITE, M. G.A. A simulação com modelo físico como modo de identificação das prioridades declaradas dos usuários no projeto da habitação de interesse social. Dissertação (Mestrado em Arquitetura e Urbanismo), Universidade Estadual de Londrina. Paraná. P. 159. 2016

\section{AGRADECIMENTO}

À Secretaria do Idoso da cidade de Londrina, que colaborou com esta pesquisa cedendo sua estrutura física e a possibilidade de contato com o grupo de idosos que frequentam o Centro de Convivência do Idoso (CCl) da Zona Oeste.

\section{NOTAS}

${ }^{1}$ De acordo com o Ministério da Previdência Social, da Secretaria de Estado de Assistência Social, em seu documento sobre Normas de Funcionamento de Serviços de Atenção ao idoso no Brasil, por envelhecimento, entende-se o aumento da proporção da população idosa no total da população geral, provocado pela queda de fecundidade e pelo aumento da longevidade. Isso se dá em detrimento à diminuição do peso da população jovem no total populacional. $O$ aumento da longevidade, também em curso, contribui para que esse segmento viva por um tempo maior (BRASIL, 2001).

${ }^{2}$ Nesse levantamento foi identificada a área média e o desenho dos projetos produzidos, para delimitar uma proposta de projeto à aplicação ser aplicado na simulação. O critério de escolha do projeto foi a limitação em seu programa, composto por no máximo três dormitórios, que fossem identificados pelas construtoras como empreendimentos para a classe média, e que tivessem áreas médias privativas inferiores a $100 \mathrm{~m}^{2}$. Essas características representam a maioria dos empreendimentos lançados nesse período da pesquisa conforme levantamento nos sites das construtoras.

NOTA DO EDITOR (*) O conteúdo do artigo e as imagens nele publicadas são de responsabilidade do(s) autor(es). 